Revista de Comunicación y Salud, 2020, Vol. 10, oㅡ 2, pp. 417-429

Editado por Cátedra de Comunicación y Salud

ISSN: 2173-1675

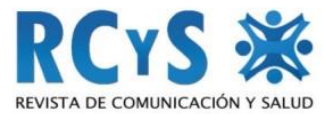

Enviado 15/08/2020

Aprobado 29/09/2020

\title{
DESDE EL ESTALLIDO SOCIAL CHILENO A LA PANDEMIA COVID-19: APROXIMACIONES DE UN CAMBIO PROFUNDO
}

\section{From de Chilean social outbreak to the COVID-19 pandemic: approaches of a deep change}

\author{
Loreto González Suazo1 \\ Universidad de Valparaíso Chile \\ loretogonzalezsuazo.20@gmail.com
}

\section{Resumen}

En Octubre de 2019 Chile comenzó a experimentar un proceso de profunda crisis social, política y económica que detonó por el alza en el precio del transporte público, una de las frases más citadas durante el comienzo de la crisis era "no son 30 pesos, son 30 años", indicando que la crisis no solo se explica por el aumento del transporte, sino por la suma agobiante de desigualdades que el pueblo chileno viene experimentando hace más de 40 años, esto se expresa por el endeudamiento extremo de los hogares, la alta morosidad y bajos salarios, la detestable distribución de la riqueza.

Palabras clave: Estallido social; Crisis modelo neoliberal; COVID-19; Salud pública.

\section{Abstract}

In October 2019, Chile began to experience a process of deep social, political and economic crisis that was triggered by the rise in the price of public transport, one of the most frequently quoted phrases during the beginning of the crisis was "it's not 30 pesos It's 30 years, "indicating that the crisis is not only explained by the increase in transportation, but by the overwhelming sum of inequalities that the Chilean people have been experiencing for more than 40 years, this is expressed by the extreme indebtedness of households, the high delinquency and low wages, the detestable distribution of wealth.

Keywords: Social outbreak; Neoliberal crisis model; COVID-19; Public health.

1 Autora para correspondencia: Loreto González Suazo, Universidad de Valparaíso, loretogonzalezsuazo.20@gmail.com. 
Desde el estallido social chileno a la pandemia COVID-19: aproximaciones de un cambio profundo

\section{Cómo citar el artículo}

González Suazo, L. (2020). Desde el estallido social chileno a la pandemia COVID-19: aproximaciones de un cambio profundo. Revista de Comunicación y Salud, 10 (2), 417-429. doi: https://doi.org/10.35669/rcys.2020.10(2).417-429

\section{INTRODUCCIÓN}

El presente artículo tiene como objetivo describir los principales hechos que ha experimentado Chile durante el pasado octubre de 2019 a propósito del "Estallido Social" ciudadano y cómo este "Estallido Social" se ha visto profundizado con la pandemia de COVID-19. Este desafío requiere esfuerzos de revisión, ya que abordar temáticas de crisis sociales, crisis de legitimidad y tiempos de pandemia necesitan de una especial atención y cuidado.

Ha sido este interés el que ha tenido este artículo para describir los principales hechos desde el estallido social chileno a la pandemia COVID-19, para poder aproximarnos a un cambio profundo que está viviendo nuestra sociedad, lo que permite tensionar las lógicas del modelo neoliberal imperante e identificar dimensiones claves para repensar otra sociedad para Chile.

\section{OBJETIVO GENERAL}

Describir los principales hechos que ha experimentado Chile durante octubre de 2019 a propósito del "Estallido Social" y cómo el "Estallido Social" ha mostrado las desigualdades de un Sistema Político y Económico que en pandemia COVID-19 se ha profundizado.

\section{DESARROLLO DE LA INVESTIGACIÓN}

\subsection{El Inicio de Todo: Nuestro Contexto}

Durante más de 40 años Chile ha sido el escenario de un profundo experimento económico y social. Durante la Dictadura Militar en septiembre de 1973 y por cierto todo el tiempo que esta duró, Chile experimentó una cruenta represión de dirigentes políticos y sociales, Pérez (2014, p. 42) señala que "los ministros civiles del gobierno militar pudieron despejar brutalmente toda traba institucional e implementar, gobernando a través de decreto leyes, un modelo económico completamente ajeno a la tradición chilena". Muchas de las políticas y formulas sociales pensadas por los teóricos neoliberales que se instalaron en Chile durante la dictadura militar, fueron aplicadas por primera vez en Chile y desde ahí se fueron predicando e instalando al quehacer chileno. Esto hizo que Chile un país con una escasa población dieciséis millones en 2012, y con una economía esencialmente menor a pesar de sus innegables recursos naturales, se fue convirtiendo en un verdadero modelo para la nueva derecha mundial. Según Pérez (2014, p. 43) el "éxito" de este modelo que se empezó a instalar en 
Desde el estallido social chileno a la pandemia COVID-19: aproximaciones de un cambio profundo

dictadura y que fue profundizado durante los gobiernos de la concertación sólo fue encubriendo una "enorme catástrofe social para los más amplios sectores del pueblo chileno, y un modo de grosera depredación y saqueo de sus riquezas"

Pérez (2014, p. 43) señala que entre los años 2006 y 2011 las grandes compañías mineras extranjeras se habían llevado de Chile más de 160.000 millones de dólares en ganancias. Pérez (2014, p. 43) afirma que según los datos del Servicio de Impuestos Internos (SII), el $99 \%$ de los chilenos vive con un salario promedio de 680 dólares $(\$ 339.680)$, el otro $1 \%$ con un salario promedio de 27.400 dólares $(\$ 13.703 .000)$, es decir, 40 veces mayor"

Estos datos que nos muestra el autor nos permiten entender el fraude que se esconden tras el discurso macroeconómico, lo que intentaremos aquí es describir en qué ha consistido esta profundización del modelo neoliberal durante los últimos 30 años para así vincularlo con las manifestaciones y el despertar chileno de octubre 2019 y los efectos de la pandemia COVID-19.

\subsection{La Primera Etapa Neoliberal Chilena.}

El primer hecho evidente de la etapa neoliberal chilena fue la privatización de activos del Estado y la reducción del gasto estatal. Todo esto ocurrido con la violencia militar que caracterizó a las dictaduras militares de Latinoamérica en los años 70, por otro lado Pérez (2014, p.44) afirma que la "corrupción civil que, amparada en esa posición de fuerza, privatizó y desnacionalizó las riquezas y los aparatos productivos estatales tras décadas de economías desarrollistas". Lo que nos indica el autor es la primera aproximación que luego se vuelve mucho más profunda en una segunda etapa que dice relación con la consolidación del modelo neoliberal como un modelo ejemplar a seguir y que es necesario criticar y analizar, ya que está presente hasta nuestros días evidenciando que ya Chile necesita de otra forma o pacto social, el cual se está gestando para los próximos 50 años.

Es necesario exponer y denunciar sobre todo para dejar el descubierto, Según Pérez (2014, p. 44) afirma que:

uno de los principales mitos de la crítica anti neoliberal imperante: el modelo neoliberal NO fue impuesto, ni fue hecho eficaz y viable, a partir y a través de dictaduras militares. Su verdadera eficacia y profundidad ha sido implementada progresivamente a través de gobiernos civiles, por medios "democráticos", y por coaliciones políticas que proclaman ser de "centro izquierda".

En este sentido la política del shock menciona Pérez $(2014$, p. 45) se relaciona con lo siguiente:

1. Las políticas de precarización del empleo y el debilitamiento de los derechos laborales

2. Las políticas de privatización de las ramas de la producción en manos del Estado

3. Una política general de desnacionalización de los recursos naturales

Revista de Comunicación y Salud, 2020, Vol. 10, nº 2, pp. 417-429 
Desde el estallido social chileno a la pandemia COVID-19: aproximaciones de un cambio profundo

4. Una política general de liberalización del comercio mundial, de apertura arancelaria, congruente con las nuevas formas de organización distribuida a nivel mundial.

Esta política del shock que menciona el autor no es más que por ejemplo la precarización del trabajo, la cual se presenta como un "fomento" o "generación de nuevos empleos" a jóvenes, mujeres, pobres, profesionales universitarios recién egresados, van creando una tendencia, acompañada de una pomposa campaña de propagandas, Según Pérez (2014, p. 46) afirma que:

en que se debilitan por sectores los derechos laborales tradicionalmente adquiridos a través de prolongadas luchas de los trabajadores. Una propaganda que sostenidamente afirma favorecer el empleo, hacer viable la economía, abrir nuevas posibilidades de adelanto económico de los individuos y las familias, sin hacerse cargo en absoluto ni de la calidad del empleo que favorecen, ni de los bajos niveles salariales implicados, ni de la absoluta falta de derechos laborales y sindicales que los rodean

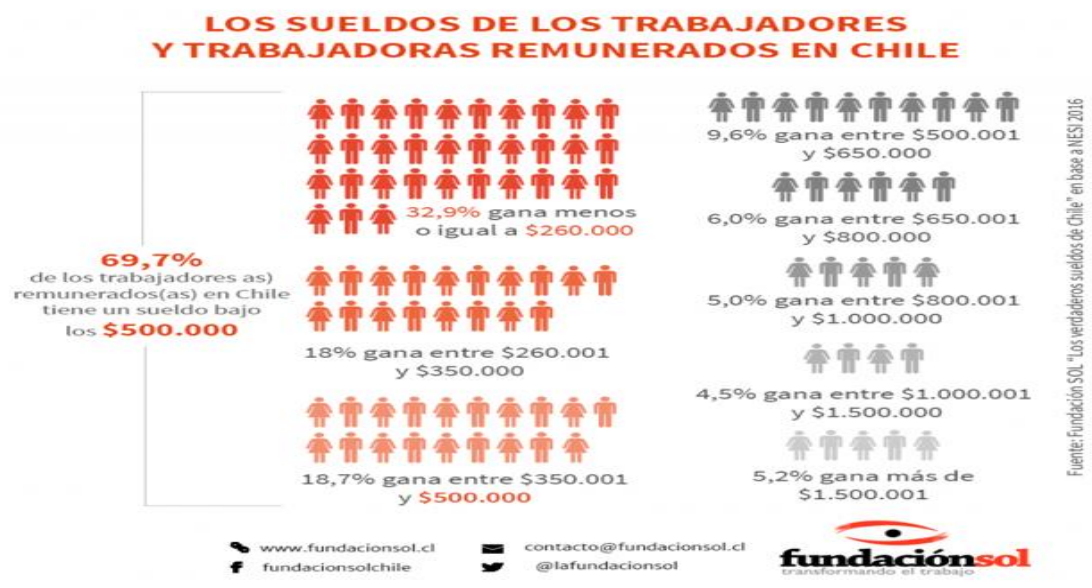

Figura 1. Los sueldos de los trabajadores y trabajadoras remunerados en Chile Fuente: Fundación Sol "Los verdaderos sueldos en Chile" en base a NESI 2016

\subsection{El Despertar Chileno: Revuelta Social y Emergencia Sanitaria COVID-19}

Todo lo anterior expuesto se puede entender como una "megacrisis", Soublette (2020, p. 10), señala que este contexto cubre hoy todo el mundo, ecualiza todo el acontecer social en una misma fenomenología en donde las diferencias culturales que antes distinguían a los pueblos entre sí por sus usos y costumbres hoy han desaparecido. Esta desaparición es la que es la Chile, ha vivido durante los últimos 40 años en un régimen en donde el gran capital ha logrado convertir en áreas de negocios los derechos sociales, Pérez (2014, p. 51) señala "que tenían que ser proveídos y garantizados por el Estado". Esta mercantilización y privatización de los servicios básicos que resulta de estas políticas y que recaen directamente en los usuarios, el abandono del Estado de estos bienes esenciales, empieza a quedar de manifiesto en los movimientos sociales del 2006 con la revolución pingüina, el 2011 con la primavera 
Desde el estallido social chileno a la pandemia COVID-19: aproximaciones de un cambio profundo

de Chile y el despertar universitario por los exceso de lucro en la educación, terminan por profundizarse y colmarse en el despertar chileno de octubre de 2019 que al parecer no tiene vuelta atrás, en donde queda totalmente claro que la ciudadanía tiene cuatro principales áreas sensibles que le son comunes: el transporte público, la educación, la salud y las pensiones.

Estos cuatros áreas sensibles es que pretendemos abordar durante este apartado y también empezar a describirlas y analizarlas a la luz de la Emergencia Sanitaria COVID-19. Pues bien, "Chile despertó", "Crisis en Chile de 2019", y "Revolución de los 30 pesos": Este despertar social acontecido en Chile, tuvo como detonante una serie de desigualdades en el acceso al sistema de transporte público, el cual se denominó la "revolución de los 30 pesos", iniciada esta por estudiantes de secundaria, lo que dio pie para el alzamiento generalizado de la ciudadanía, que venía experimentando más de 40 años de desigualdades sociales, políticas, y económicas, las cuales son hasta el día de hoy protegidas por la carta fundamental creada en Dictadura Cívico Militar.

Una vez iniciado el despertar de la ciudadanía chilena, el gobierno de Sebastián Piñera "respondió al descontento social y a las manifestaciones con medidas represivas, sacando a los militares a la calle durante varios días". Estas primeras actitudes del gobierno de Sebastián Piñera para abordar el malestar social que comenzaba a experimentar Chile, mostraba que desde los intersticios de la sociedad civil se hacen preanuncios cada cierto tiempo de dicho malestar como lo señala Madariaga (2019, p. 146) señala que fue: "la revolución pingüina, las luchas del pueblo mapuche contra el Estado y la poderosa industria maderera por sus tierra y la libertad de sus loncos, dirigentes y comuneros encarcelados, las marchas multitudinarias de los estudiantes universitarios por el derecho a la educación, los ciudadanos contra las AFP, las mujeres por la igualdad de género y sus derechos sexuales y reproductivos", han sido los hechos acumulativos que han hecho estallar el malestar social y que muestra la fuerza de los movimientos sociales chilenos, los cuales emergen y se articulan en la medida de que los fenómenos sociales se complejizan. En estos casi ya nueve meses de haberse producido el estallido social chileno y que ahora solo se mantiene el "encierro" debido a la emergencia sanitaria del COVID-19, podemos visualizar que ahora existe un nuevo sujeto público, el cual se ha convertido en un actor social relevante con una voluntad de poder y decisión de cambio que inaugura una nueva construcción de una conciencia social, Según Madariaga (2019, p. 147) esto es una "racionalidad que orienta la acción ciudadana hacia la reflexión crítica y la gestación de una demanda final: un nuevo pacto social mediante asamblea constituyente y nueva constitución política". Hemos de esperar que este sujeto que está en plena construcción de si mismo y del nuevo pacto social del que nos habla el autor, pueda lograr la materialización de sus propósitos transformativos.

\subsection{La Crisis Social y Los Efectos en la Salud Pública}

Tal como hemos venido describiendo, la crisis social chilena sin duda ha afectado enormemente la salud pública y saludad mental de todos los chilenos y chilenas. El

Revista de Comunicación y Salud, 2020, Vol. 10, nº 2, pp. 417-429 
Desde el estallido social chileno a la pandemia COVID-19: aproximaciones de un cambio profundo

carácter nacional del estallido social que ha sido capaz de convocar a todo un territorio, en donde su fuerza y multitudinaria participación de diferentes organismos de la sociedad civil. Según Madariaga (2019, p. 150) "importantes sectores de la ciudadanía han quedado expuestas en forma sostenida a condiciones de máxima exigencia psicoemocional y al peligro diario de ser afectados por la represión policial". Estos efectos psicoemocionales que se agudizan ahora en el "encierro" por la emergencia sanitara COVID-19, nos evidencia que Chile, está viviendo dos transformaciones profundas, una de ellas la que dice relación con el estallido social y los más de 40 años de desigualdades sociales, políticas y económicas y la segunda crisis de emergencia sanitaria COVID - 19 que visibiliza y aumenta aún más el malestar de la ciudadanía. En este sentido podemos ver que Chile está pasando por un período doble de crisis el cual según Madariaga (2019, p. 150) se visualiza en "eventos traumáticos de distinto tipo y nivel de gravedad, que afectan tridimensionalmente la corporalidad (sus aspectos biológicos, psicológicos y sociales), del mismo modo que se proyectan en forma expansiva desde el sujeto individual"

Estos efectos tanto de la crisis social como los efectos que trae la emergencia sanitaria del COVID-19, es muy preocupante porque los y las chilenos se han visto expuesto a procesos de violencia traumática que afecta a la sociedad en su conjunto.

Esta violencia represiva que ha experimentado la sociedad chilena es de tipo cíclica en donde se reproducen según Madariaga (2019, p. 150) "políticas de control y sumisión social, ciclos que no nacen con la experiencia de Pinochet y el terrorismo de Estado, sino que se inauguran con la invasión colonial y se repiten cada cierto tiempo desde la fundación del Estado Nación chileno". De esta forma, podemos advertir que Chile ha vivido una arqueología de violencia histórica, que está instalada en las subjetividades sociales y también en la producción del malestar y la enfermedad.

Hemos vivido más de medio siglo una experiencia de traumatización social extrema. Madariaga (2019, p.150) afirma que esta violencia fue:

Inaugurada con el golpe cívico - militar de 1973, que instala casi dos décadas de terrorismo de Estado; las generaciones que fueron víctimas de ese período histórico llevan consigo una carga de enfermedad y muerte que los transforma en grupos vulnerables, especialmente aquellas personas y familias que vivieron traumas graves (tortura, asesinato y desaparición de familiares, exilio, prisión política, etc.).

\subsection{La Gestión de la Pandemia COVID-19 en Chile}

Si vamos enlazando que Chile desde octubre 2019 hasta inicios de marzo del 2020 ha venido experimentando una serie de cambios profundos, en lo que respecta a la gestión de la pandemia COVID-19 y cómo esta ha sido manejada durante los primeros meses que fueron detectándose los casos de contagios, podemos señalar según Heiss $(2020$, p . 3) que "la reticencia inicial del gobierno a tomar medidas de aislamiento social pareció sugerir que seguiría el modelo británico de inmunidad "de rebaño", es decir, buscar que la exposición de la población al virus generase inmunidad"

Revista de Comunicación y Salud, 2020, Vol. 10, nº 2, pp. 417-429 
Desde el estallido social chileno a la pandemia COVID-19: aproximaciones de un cambio profundo

Tal como se observa, en Chile la estrategia principal para poder gestionar la pandemia fue hacer que la propia población regulara su movilidad para poder prevenir el contagio del virus. Sin embargo, a casi dos semanas de haber comenzado la pandemia, las autoridades comenzaron a dar directrices y soluciones intermedias, lo que significó seguir un camino de confinamiento gradual y episódico a diferencias de países como Nueva Zelanda o Noruega, que llamaron a su población al confinamiento obligatorio y de nivel nacional.

De esta forma Heiss (2020, p. 3) nos señala que "el 16 de marzo, el presidente Sebastián Piñera, acompañado del ministro de Salud, Jaime Mañialich, anunció el ingreso a la Fase 4 de la pandemia, con 156 personas contagiadas y la imposibilidad de rastrear el origen de la infección", imposibilidad que fue muy compleja de rastrear debido a que no se tenían los suficientes recursos e infraestructura sanitaria para poder comenzar con los análisis de PCR haciendo compleja la trazabilidad del virus, esto además aparejado con el hecho de que el gobierno a propósito de esta Fase 4 comienza a cerrar fronteras, suspender clases en establecimientos de educación, comenzar con las cuarentenas obligatorias para personas ya contagiadas, reducción de número de personas en actos públicos y sanitización del transporte público, para luego dos días después decretar Estado de Excepción Constitucional de Catástrofe.

Luego del primer mes de pandemia en Chile, los primeros análisis han sugerido según Heiss (2020, p. 3):

que el país ha controlado el COVID-19 de manera más efectiva que otros de la región. El ministro Mañialich ha dicho que se cuenta con suficientes tests de PCR y ventiladores mecánicos para enfrentar el punto álgido de la curva de la enfermedad. Estos equipos llegarían a los 3.300, si se incluyen los del sector privado.

Según lo citado, se puede observar que en Chile durante los primeros meses las autoridades señalaban contar con los recursos suficientes para controlar la pandemia y que "aplanar la curva" de la enfermedad estaría controlada, de hecho, en marzo el banco de inversiones J.P. Morgan señalaba en su informe titulado "Chile vs COVID-19: medidas iniciales muestran resultados alentadores, este informe señala principalmente las fortalezas que tuvo Chile al implementar las estrategias para controlar la pandemia, estas según Heiss (2020, p. 4) eran:

medidas preventivas tempranas y que se ha aplicado a un alto nivel de testeo de presencia del virus, lo que daría cifras más cercanas a la realidad de las que tienen otro países Estados, agrega que hay un alto número de personas infectadas, pero con baja letalidad. Como ejemplo se menciona que a ocho días del primer caso había solo siete víctimas, en comparación con 35 en Italia, 84 en España y 57 en Brasil

Sin embargo, frente a esta realidad optimista que señala el informe y las autoridades chilenas, existen también analistas que tienen una visión mucho más pesimista respecto de la baja letalidad del virus en los casos chilenos. Una de las voces más

Revista de Comunicación y Salud, 2020, Vol. 10, oㅡ 2, pp. 417-429 
Desde el estallido social chileno a la pandemia COVID-19: aproximaciones de un cambio profundo

críticas respecto del manejo de la pandemia en Chile, ha sido la Doctora Iskia Siches, presidenta del Colegio Médico de Chile, la cual se ha mostrado crítica sobre el manejo que ha tenido el gobierno sobre la pandemia. En este contexto en un medio de comunicación la presidenta del Colegio Médico sostenía que 2“ la estrategia de gobierno de diagnosticar para contener la expansión del COVID-19 es imposible de implementar a la fuerza porque nuestros médicos, que se encuentran a lo largo de la red asistencial, no han informado que existen problemas relevantes de saturación de la capacidad diagnóstica y que no se están aplicando los protocolos mandatados por la autoridad sanitaria, no por desacato sino por problemas de implementación". En efecto, lo planteado por la presidenta del Colegio Médico, muestra que la comunidad médica de Chile, al comienzo de la pandemia, se encontraba preocupada porque desde el colegio médico se señalaba que no contaban con toda la información para colaborar con el gobierno.

Los datos aportados eran incompletos, inconsistentes y tenían una tremenda falta de transparencia que no se había visto en la historia institucional de la salud pública chilena. Heiss (2020, p. 4) afirma que:

en una fase más avanzada se podría saturar el sistema de salud, lo que generaría dos fenómenos adicionales: se testearía menos y aumentaría la letalidad. En otras palabras, "no es posible prever cómo va a evolucionar la situación cuando los casos se expandan entre grupos más vulnerables de la población.

Como puede observarse tanto lo planteado por la presidenta del colegio de médico como por la autor Heiss, nos señala que la pandemia y su gestión durante los primeros meses en Chile fue un manejo tardío y en cierta forma torpe al percibir que incluso los mismos profesionales de la salud pública chilena manifestaban desde el comienzo el colapso de los sistemas sanitarios, es decir, según Heiss (2020, p. 4) los mismos "trabajadores de la salud se quejaban de la falta de insumos básicos como mascarillas. Hasta el 8 de abril se sabía que 286 funcionarios de salud contagiados la gran mayoría de ellos pertenecientes a la red de salud pública"

Ahora bien, respecto de la capacidad del sistema de salud Heiss (2020, p. 5) afirma que:

se ha criticado el confuso anuncio de una compra de ventiladores mecánicos cuya fecha de arribo es incierta, así como la escasa información sobre la forma en que toman las decisiones relativas al manejo del COVID-19. Por ejemplo, el gobierno ha señalado que la máxima tasa de contagios se producirá entre fines de abril y comienzos de mayo, pero no ha compartido los criterios usados para ese pronóstico.

${ }^{2}$ Fuente: https://www.poderyliderazgo.cl/presidenta-del-colegio-medico-califica-de-fracaso-estrategia-delgobierno-por-coronavirus/ consultado 19 de agosto de 2020.

Revista de Comunicación y Salud, 2020, Vol. 10, oㅡ 2, pp. 417-429 
En consecuencia a lo anterior expuesto, es que aún la pandemia del COVID-19 en Chile, sigue estando en proceso ${ }^{3 " m a r t e s} 18$ de agosto del 2020, el Ministerio de Salud reporta 1.336 casos nuevos de COVID-19, de los cuales 846 corresponden a personas sintomáticas y 443 no presentan síntomas. Además, se registraron 47 test PCR Positivo que no fueron notificados". Respecto de las cifras de fallecidos el reporte indica que 4"La cifra total de personas que han sido diagnosticadas con COVID-19 en el país alcanza a las 388.885.

De ese total, 15.869 pacientes se encuentran en etapa activa del virus. Los casos recuperados son 362.440 . En cuanto a los decesos, de acuerdo a la información entregada por el Departamento de Estadística e Información de Salud (DEIS), en las últimas 24 horas se registraron 33 fallecidos por causas asociadas al COVID-19. El número total de fallecidos asciende a 10.546 en el país".

\subsection{Las Medidas Económicas y Sociales del COVID-19 en Chile}

Al mismo tiempo que el gobierno intentaba gestionar la pandemia y mantener la curva controlada, las medidas económicas y sociales en el contexto de pandemia, también comenzaron a ser importantes a la hora de realizar los análisis sociales pertinentes. Así en este sentido es que muchos países de Latinoamérica han de recurrir al FMI (Fondo Monetario Internacional), para buscar recursos y contener esta crisis sanitaria y social, sin embargo en el caso de Chile, estas medidas no incurren en aumentar el gasto público, sino que los principales anuncios del gobierno han estado centrado en el aumento al acceso al crédito en la banca privada, reasignar fondos al sector salud desde otros 425 ítems de la billetera fiscal y emplear fondos individuales del seguro de cesantía. En este sentido Chile para contener esta pandemia no ha recurrido a la ayuda externa ni al endeudamiento, esto se explica en el siguiente gráfico:

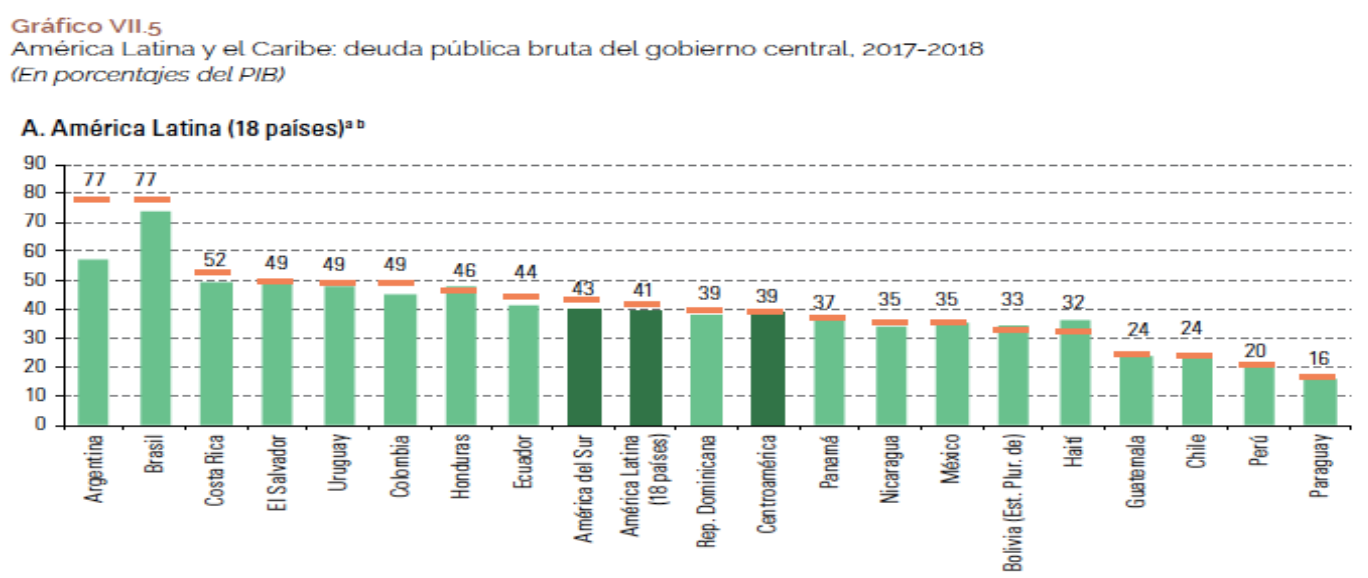

Figura 2. ${ }^{5}$ América Latina y el Caribe: deuda pública bruta del gobierno central, 2017-2018 (En porcentaje PIB)

Fuente: Elaboración propia

\footnotetext{
${ }^{3}$ Fuente: www.minsal.cl Reporte Mes de Agosto COVID-19 Ministerio de Salud de Chile

${ }^{4}$ Fuente: www.minsal.cl Reporte Mes de Agosto COVID-19 Ministerio de Salud de Chile

${ }^{5}$ Fuente: CEPAL 2019: Informe Balance Preliminar de las Economías de América Latina y el Caribe
} 
Desde el estallido social chileno a la pandemia COVID-19: aproximaciones de un cambio profundo

Este gráfico nos muestra que la deuda pública bruta en el caso de Chile, corresponde al 24\% de su PIB, uno de los más bajos de la región (CEPAL, 2019,p. 86). Esto nos da inferir que Chile tiene un margen para endeudarse y poder enfrentar la pandemia sin necesidad de recurrir al FMI. El fisco podría, por ejemplo, según Heiss (2020, p.5) emitir:

Deuda en mercados financieros internacionales. También podría recurrir a los 12.400 millones de dólares que posee en el Fondo de Estabilización Económica y Social, que existe precisamente para evitar el endeudamiento ante situaciones de crisis, y que equivale a alrededor del $4 \%$ del PIB.

Sin embargo, las medidas anunciadas hasta el momento son tímidas en comparación con otros países de América Latina.

En este sentido el gobierno de Chile, durante el mes de marzo propuso un plan económico para poder enfrentar el COVID-19, el cual tenía tres principales ejes: el primero era reforzar el presupuesto del sistema de salud, el segundo eje era proteger los ingresos de las familiar, mediante el seguro de cesantía y la entrega de 58 dólares por familia, las personas que estuvieran realizando teletrabajo podrían recibir parte de su seguro de cesantía siempre que existiese un acuerdo entre el empleador y haya un mandato de la autoridad sanitaria, el tercer eje se orientaba a las pequeñas y medianas empresas, considerando medidas tributarias que se referían a postergación de pagos.

Mientras desde el sector oficialista celebraban estas medidas adoptadas por el gobierno de Sebastián Piñera, Heiss (2020, p. 8) afirma que algunos economistas como:

Andrea Repetto objetó que el pago proveniente del seguro de cesantía del trabajador no es un gasto sino un préstamo, que provendrá de las cuentas individuales del seguro de cada trabajador o trabajadora. "Esta política no da seguridad porque si después pierden su trabajo, no van a tener cómo financiar ese desempleo, pues usaron los fondos durante la crisis para pagar su propio sueldo", señaló. Por otro lado, para quienes no tienen seguro de cesantía porque no cuentan con contratos laborales, el único beneficio es el bono que se entregará una vez. "Esas personas necesariamente tendrán que salir a trabajar y el esfuerzo de la cuarentena va a resultar ineficaz".

Luego de anunciado este plan económico, la oposición no demoró en proponer otro plan económico el cual constaba de 4 ejes principales los cuales dicen relación con: establecer una renta básica de emergencia para todas las familias mientras dure la pandemia; postergación de los pagos y prohibir los cortes de servicios básicos, postergar sin intereses las cuotas de créditos y controlar transitoriamente precios de algunos productos para evitar el acaparamiento; un tercer eje tiene que ver con el apoyo estatal a las empresas incluyendo préstamos con aval del Estado para pequeñas y medianas empresas; y por último prohibir el despido de trabajadores/as e inyectar recursos estatales en empresas estratégicas a cambio de participación estatal en ellas.

Revista de Comunicación y Salud, 2020, Vol. 10, nº 2, pp. 417-429 
Desde el estallido social chileno a la pandemia COVID-19: aproximaciones de un cambio profundo

Este plan opositor al propuesto por el gobierno requería una cantidad de recursos fiscales sin precedentes, por lo que la oposición consideraba según Heiss (2020, p. 9) que:

Chile estaba preparado para endeudarse" para reducir los costos de la crisis sanitaria. Una vez pasada esta, es necesario un nuevo pacto fiscal progresivo para reducir el mayor déficit fiscal que se generará. "Pero si no se actúa con audacia hoy, el gasto futuro será mayor y vendrá acompañado de dolorosos costos sociales.

De los anteriores planteamientos se puede deducir que, los anuncios del gobierno chilenos han buscado moderar los efectos recesivos que ha traído la pandemia, sin incurrir en el gasto público como el que sería necesario mantener a las familias en un confinamiento total. De alguna forma la responsabilidad del estado de Chile ha sido débil en el sentido de que no ha puesto todos sus esfuerzos por resguardar la salud de la población, y además esta crisis ha estado aparejada con un proceso constituyente en marcha que ha puesto a Chile en una aproximación a un cambio profundo.

\subsection{Acercándonos al Plebiscito de Octubre 2020}

Tal como hemos visto en los planteamientos anteriores, y cómo la pandemia ha puesto todo en pausa en nuestro país, se nos acerca un momento nuevamente histórico en nuestra historia y es el que dice relación con el próximo plebiscito de octubre 2020 que nació en medio del remezón social y político que vivimos también en octubre de 2019. Esto es un proceso histórico de relevancia incluso desde el retorno a la democracia en 1990. Como resultado de la revuelta social el 15 de noviembre del 2019 los partidos políticos de todo el espectro ideológico acordaron un conjunto de propuestas para hacer posible el cambio de la Constitución de 1980, impuesta durante la Dictadura de Augusto Pinochet. Muchos sectores señalan que los efectos de la pandemia podrían debilitar el proceso constituyente por el hecho de que la pandemia podría quitar el protagonismo al plebiscito e incluso podría suceder que aumentará la aprobación del gobierno.

Sin embargo, parece poco probable que las demandas por un cambio estructural en la sociedad chilena vayan a desaparecer producto de la pandemia COVID-19, es más en un contexto de recesión económica, malestar y descontento social con las instituciones políticas y sus elites podría surgir con mayor fuerza el proceso constituyente.

Por lo tanto se vuelve difícil poder prever lo que sucederá con la pandemia COVID19 y el proceso constituyente en curso, podríamos pensar que el COVID-19, podría reforzar un cambio estructural que ya hace más de 40 años Chile está esperando y además podríamos pensar que esta pandemia expone la evidente debilidad de los sistemas de protección social chileno, puso de manifiesto las miserables pensiones de nuestros adultos mayores, la precarización del trabajo y sus casi nulos derechos laborales, por mencionar aspectos que han estado en el centro del debate a partir de la pandemia del COVID-19.

Revista de Comunicación y Salud, 2020, Vol. 10, nº 2, pp. 417-429 
Desde el estallido social chileno a la pandemia COVID-19: aproximaciones de un cambio profundo

\section{CONCLUSIONES}

La llegada de la pandemia COVID-19 en Chile, tuvo lugar en un contexto de pleno estallido social, en donde la ciudadanía tenía y tiene un profundo malestar social el cual se expresa por la crisis de legitimidad de las instituciones y sus élites gobernantes, las profundas desigualdades de un sistema político, económico y cultural que ha profitado por años de la fuerza de trabajo de chilenos y chilenas en donde e individualismo y el consumo era el modo de habitar y existir en Chile. A todo aquello y mucho más ha despertado el pueblo chileno. Pero si entramos al escenario postpandemia que si en algún momento tendremos que enfrentar, es posible pensar en lo siguiente: la desmovilización social, podría favorecer a las fuerzas de la derecha con miras al plebiscito de octubre, en el entendido de que estas fuerzas de derecha construyan un discurso de unidad que ayude a salir del proceso de crisis sanitaria, es posible que el apoyo por una nueva Constitución se resienta. Un segundo posible escenario es el que dice relación con que la pandemia COVID-19 esté controlada y pueda dejar de ser el foco en nuestra sociedad, puede que retomen las fuerzas de oposición y apunten a las debilidades de la economía de mercado, las fragmentaciones y desigualdades del sistema de salud y la falta de políticas universales que resguarden los derechos sociales de los y las chilenos. Si este caso sucede veremos un proceso de cambio profundo y la creación concreta y real de un nuevo pacto social para Chile. Pero sin embargo estamos aún en proceso de caminar paralelo y que no tenemos certeza de lo que sucederá, lo que sí es posible asegurar, es que en un contexto de enorme descontento, limitaciones del sistema y los resultados adversos que se han visualizado, podrían exacerbar el descontento social y aumentar las presiones reformistas.

\section{REFERENCIAS}

CEPAL, N. (2019). Balance Preliminar de las Economías de América Latina y el Caribe 2018. CEPAL. http://hdl. handle.net/11362/45000

Heiss, C. (2020). Chile:entre el estallido social y la pandemia. Análisis Carolina,(18), 1-14. Recuperado de https://www.fundacioncarolina.es/wp-content/uploads/2020/04/AC18.2020.pdf

Madariaga, C. (2019). El "Estallido social" y la salud mental de la ciudadanía: Una apreciación desde la experiencia PRAIS. Revista Chilena de Salud Pública, 23(2), 146-156. Recuperado de https://revistasaludpublica.uchile.cl/index.php/RCSP/article/view/56475

Soto, C. P. (2014). Marxismo: aquí y ahora. Editorial Triángulo.

Soublette, G. (2020). Manifiesto: peligros y oportunidades de la megacrisis. Santiago de Chile: Ediciones UC.

Fundación Sol. www.fundacionsol.cl 
Desde el estallido social chileno a la pandemia COVID-19: aproximaciones de un cambio profundo

Diario Electrónico https://www.poderyliderazgo.cl/presidenta-del-colegio-medico-calificade-fracaso-estrategia-del-gobierno-por-coronavirus/ consultado 19 de agosto de 2020.

Ministerio de Salud, Gobierno de Chile (18 de agosto 2020). Plan de acción Coronavirus COVID-19. Recuperado de www.minsal.cl

\section{AUTORA}

\section{Loreto González Suazo}

Socióloga, Magíster en Educación mención Currículum Educacional, con experiencia probada en educación superior, específicamente en la capacitación de docentes y estudiantes en procesos de enseñanza/aprendizaje en Educación Superior. Poseo un historial en el diseño e implementación de investigaciones sociales en áreas como educación superior y metodologías de investigación social. Habilidad para trabajar en equipo y resolver problemas complejos. Habilidad para comunicar información compleja de manera simple, mediante la gestión y manejo de datos por medio de programas como Excel y SPSS. Manejo para crear y diseñar recursos pedagógicos/audiovisuales mediante tecnologías de la información y la comunicación TIC, tales como: Screecastify, Screencast; Aula Virtual/cuestionario.

loretogonzalezsuazo.20@gmail.com 